\title{
Analysis of tympanic sinus shape for purposes of intraoperative hearing monitoring: a microCT study
}

\author{
Małgorzata Bilińska' $\cdot$ Tomasz Wojciechowski ${ }^{2,3} \cdot$ Jacek Sokołowski ${ }^{2}\left[\right.$ ] Kazimierz Niemczyk ${ }^{2}$
}

Received: 24 June 2021 / Accepted: 30 October 2021 / Published online: 24 November 2021

(c) The Author(s) 2021

\begin{abstract}
Purpose Sinus tympani is the space in the retrotympanum, with variable morphology. Computed tomography is a common tool to investigate sinus tympani anatomy. During cochlear implantation or tympanoplasty, electrocochleography can be used for hearing monitoring. In such a surgical strategy the electrode is placed in the round window's region throughout posterior tympanotomy. Common accessible needle-shaped electrodes using is difficult in achieving intraoperative stabilization. The aim of the study is to assess the dimensions and shape of sinus tympani, basing on the micro computed tomography scans for purposes of establishing the possible new electrocochleography electrode shape.

Materials and methods Sixteen fresh frozen cadaveric temporal bones were dissected. MicroCT measurements included the depth and the width of sinus tympani, width of facial canal with stapedius muscle chamber. Obtained data were analyzed statistically with the use of RStudio 1.3.959 software.

Results The highest average width of sinus tympani amounted for $2.68 \mathrm{~mm}$, depth measured at the round window plane for $3.19 \mathrm{~mm}$. Width of facial canal with stapedius muscle chamber highest average values at the round window plane- $3.32 \mathrm{~mm}$. The lowest average minimum and maximum values were calculated at the $1 \mathrm{~mm}$ above the round window plane. The highest average posterior tympanotomy width was $2.91 \mathrm{~mm}$.

Conclusions The shape of the tympanic sinus is like a trough with the narrowest and deepest dimensions in the middle part. The ST shape and dimensions should be taken into account in constructing the ECochG electrode, designed for optimal placement through posterior tympanotomy approach.
\end{abstract}

Keywords Tympanic sinus $\cdot$ Temporal bone $\cdot$ Electrocochleography $\cdot$ Tympanoplasty $\cdot$ Computed tomography

\section{Introduction}

The central structure in the topography of the posterior wall of the tympanic cavity is facial nerve, or rather the corresponding pyramidal ridge. It divides the posterior wall into lateral and medial spaces. The central point (fulcrum) of the posterior wall, is the pyramidal eminence. There are two

Jacek Sokołowski

jacsokolowski@gmail.com

1 Department of Dentistry and Oral Health, Aarhus University, Midtjylland, Aarhus, Denmark

2 Department of Otorhinolaryngology, Head and Neck Surgery, Medical University of Warsaw, Banacha 1a Street, 02-202 Warsaw, Poland

3 Department of Descriptive and Clinical Anatomy, Medical University of Warsaw, Chałubińskiego 5, 02-004 Warsaw, Poland lateral and medial spaces. The lateral spaces together form the so-called facial recess. The facial recess is limited laterally by the chorda tympani running along the iter chordae posterius, and medially by the facial nerve canal. The lateral spaces are in the shape of an inverted triangle with the apex downward, where chorda tympani branches from the end of the mastoid part of the facial nerve to form chordo-facial angle. Currently, the description of the medial spaces uses a division into two areas: upper and lower retrotympanum. Upper retrotympanum involves posterior tympanic sinus and sinus tympani.

Sinus tympani (ST) is considered to be largest space in the retrotympanum. It is located medially to the pyramidal eminence, stapedius muscle, and facial nerve and laterally to the posterior semicircular canal $[2,15,26]$. The morphology varies among individuals, although factors affecting the variations in size and shape are unclear. The sinus is subject to great variability in posterior extent, in some cases, 
the dimension may extend posteriorly beyond the limits of the mastoid portion of facial nerve. The depth of sinus tympani is considered to be the most relevant morphological data [17]. Radiological examination, such as computed tomography (CT) and high-resolution computed tomography (HRCT) are commonly used to investigate pathologies of the temporal bone [3, 28, 29]. Although the anatomy of the middle ear was well evaluated in histological studies [26], investigations based on radiological examination are less common to evaluate prevalence of normal anatomical variations $[17,18,24,28]$.

Some researchers have tried to use ECochG as an intraoperative monitoring tool in middle ear surgeries [11, 19]. Hohmann suggested that it might become a promising tool to assess the function of reconstructed ossicular chain [11]. In cases of inner ear fistula, the inadvertent, unintentional, or unplanned opening of the inner ear can result in severe sensorineural hearing loss [27]. The presence of a fistula of the semicircular canals or the cochlea can be encountered during the removal of cholesteatoma and then hearing monitoring may be useful.

There is crucial during surgery to perform measurements in the shortest possible time.

One of the factors extending the duration of tympanoplasty with hearing monitoring is the placement and stabilization of a needle electrode.

For this reason, it seems beneficial to analyze the anatomy of the retrotympanum and then design a stable electrode for ECochG measurements.

\section{Aim}

The aim of the study is to assess the dimensions (width, depth) and shape of sinus tympani, basing on the micro computed tomography (microCT) scans for purposes of establishing size of the possible new ECochG electrode shape.

\section{Materials and methods}

\section{Ethical statement}

This retrospective study was approved by the Ethics Committee of Medical University of Warsaw (Decision Number $\mathrm{KB} / 69 / 2015$ ), and abides by the 1964 Helsinki Declaration and its later amendments or comparable ethical standards.

\section{Temporal bones preparation}

The research was conducted on 16 fresh frozen cadaveric temporal bones. At first, all specimens were numbered and labeled with a side. Each of them was prepared in a way to fit into the microCT scanner. The sinus tympani, otic capsule with a bony labyrinth were intact in every specimen.

All the scans were obtained with the scanner Phoenix Xray (GE Sensing \& Inspection Technologies, Niels-BohrStr. 7, 31,515 Wunstorf, Germany) with parameters: voxel dimensions $0.07 \times 0.07 \times 0.07 \mathrm{~mm}$; the exposition performed with source voltage of $120 \mathrm{kV}$ and current of $70 \mathrm{~mA}$. All scans were analyzed in RadiAnt DICOM Viewer 2020.1 (64bit) and obtained data were analyzed statistically with the use of RStudio 1.3.959 software.

\section{Measurements procedure}

In the first phase, the reference planes were established using MultiPlanar Reconstruction (MPR) option to acquire images in the planes of anterior, posterior and lateral semicircular canals (Fig. 1). Table 1 presents variables and symbols analyzed in present study and description how they are defined (Table 2).

At first, one person has established the protocol and prepared the images. Measurements were performed independently by two researchers, based only on presumed consensus. After analyzing of potential differences reasons, it was found that researchers have chosen slightly different round window measurements planes. When analyzing results the width of the round window over $1 \mathrm{~mm}$ has generated a change in the remaining measurement parameters. Therefore it was assumed that the measurement point would be the plane passing through the half of the round window membrane in the plane of the posterior semicircular canal. Repeatability of the method has been obtained in re-measurements in the all assessed parameters. After the correction in the method, there was observed statistically important correlation between measurements of Researcher No 1 and No 2 at the level of round window $1 \mathrm{~mm}$ above and one millimeter below in assessment FN + SM-1, dST_RW, dST_RW, wST_RW + 1, wPT.

For the best visualization, the medial retrotympanum requires the use of oblique sagittal plane (Pöschl projection), where temporal bone is viewed from its anteromedial to posterolateral aspects.

Poschl projection is parallel to the superior semicircular canal-it allows the identification of the cochlear promontory, round window and its posterior pillar. This projection is widely used in temporal bone studies [5, 30].

In the plane parallel to the plane of lateral semicircular canal, three sets of measurements on three different levels were obtained. Set of measurements contained of sinus tympani width (wST), depth (dST) and width of facial canal with stapedius muscle chamber $(\mathrm{FN}+\mathrm{SM})$. All these measurements were taken at the level of round window, $1 \mathrm{~mm}$ superiorly and $1 \mathrm{~mm}$ inferiorly (Fig. 2). Next, in the 
Fig. 1 Basic planes used in the study for measuring purposes. a Pöschl plane (anterior semicircular canal); $\mathbf{b}$ posterior semicircular canal plane; c lateral semicircular canal plane; SSC superior semicircular canal, $\operatorname{ArcE}$ arcuate eminence, $T C$ tympanic cavity, $L S C$ lateral semicircular canal, $V$ vestibule, IAM internal acoustic meatus, PSC posterior semicircular canal, Co cochlea

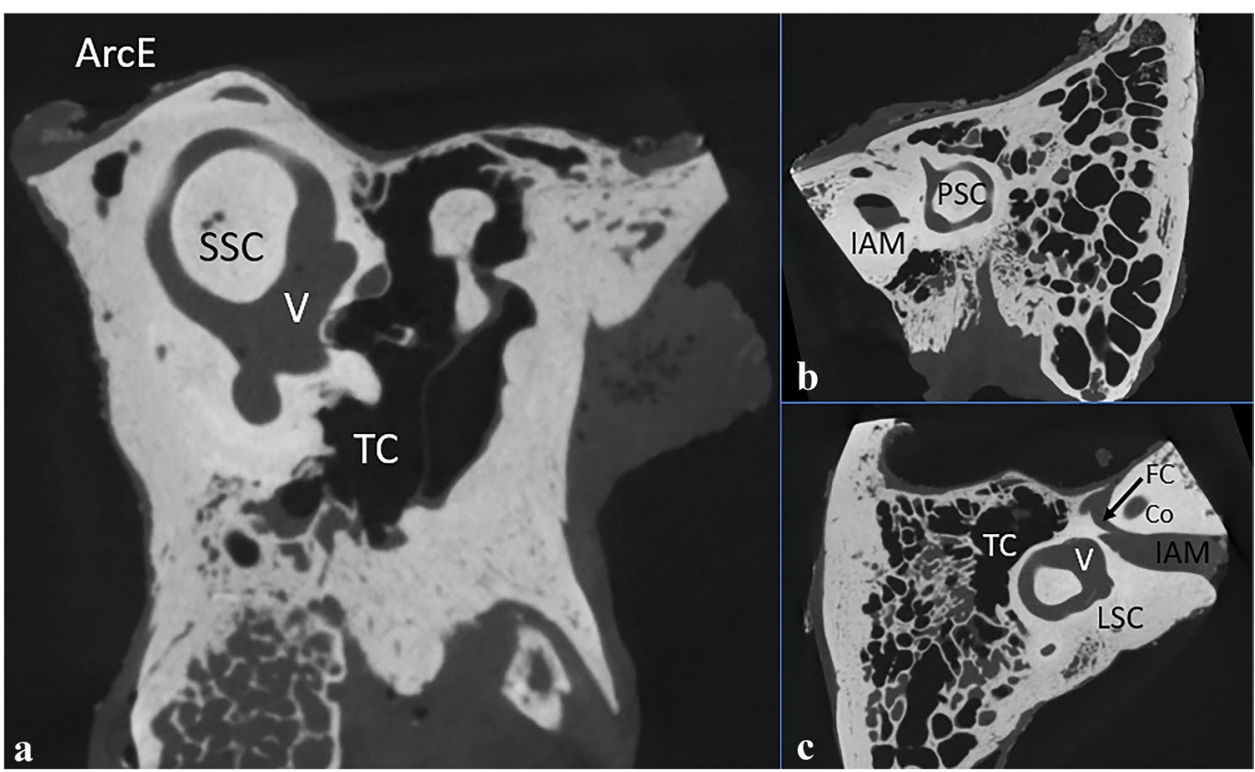

Table 1 Variables and symbols used in present study

\begin{tabular}{ll}
\hline Variable & Description \\
\hline wST & $\begin{array}{c}\text { Width of sinus tympani measured from most anterior point of pyramidal eminence/pyramidal crest to most lateral point of cochlear } \\
\text { promontory }\end{array}$ \\
dST & $\begin{array}{c}\text { Depth of sinus tympani measured from half wST distance to most posterior point of sinus tympani } \\
\text { FN + SM }\end{array}$ \\
$\begin{array}{c}\text { Width of facial canal and stapedius muscle chamber from most lateral point of facial canal to most medial point of stapedius muscle } \\
\text { chamber on the level of the round window }\end{array}$ \\
$\begin{array}{c}\text { WPT } \\
\text { Width of facial recess (probable posterior tympanotomy) at the level of iter chordae posterius (IChP) opening to tympanic cavity } \\
\text { measured from most medial point of IChP opening to most lateral point of facial canal }\end{array}$ \\
\hline
\end{tabular}

Variables and symbols used in present study and description how they are defined; $-1 /+1$ added to variable means the level superior or inferior to the round window level

Table 2 Statistical analysis of variables

\begin{tabular}{|c|c|c|c|}
\hline \multicolumn{4}{|l|}{ Kruskal-Wallis test } \\
\hline & $\mathrm{FN}+\mathrm{SM}$ & wST_RW & dST_RW \\
\hline$p$ value & 0.30 & 0.00001 & 0.57 \\
\hline \multicolumn{4}{|l|}{ Mann-Whitney $U$ test } \\
\hline Compared data/p-value & wST_RW-1 & wST_RW & wST_RW + 1 \\
\hline wST_RW-1 & $\mathrm{x}$ & 0.001 & 0.00006 \\
\hline wST_RW & 0.001 & $\mathrm{x}$ & 0.003 \\
\hline wST_RW + 1 & 0.00006 & 0.003 & $\mathrm{x}$ \\
\hline
\end{tabular}

Kruskall-Wallis test was used to calculate statistically important differences between groups only in width results ( $p$ value: 0.00001). The MannWhitney $U$ test confirmed statistically important differences between all groups within width variable

same plane, at the level of iter chordae posterius opening to the tympanic cavity, width of facial recess (probable posterior tympanotomy) was measured (wPT, Fig. 3). Combined values of wST, dST and wPT may be of help in estimation of probe diameter. The FN + SM value corresponds to possible radius of hook-shaped probe (Figs. 4 and 5). The type of tympanic sinus was assessed according to Marchioni's classification from shallow through deep to very deep tympanic sinuses [16]. 
Fig. 2 Planes used for measurements in the study $\mathbf{a} / \mathbf{b}$ Blue line shows the level of round window $(R W l v l)$, blue dotted lines show levels $1 \mathrm{~mm}$ above $(R W$ $l v l-1)$ and $1 \mathrm{~mm}$ below round window $(R W l v l-1)$, yellow line plane paralel to posterior semicircular canal
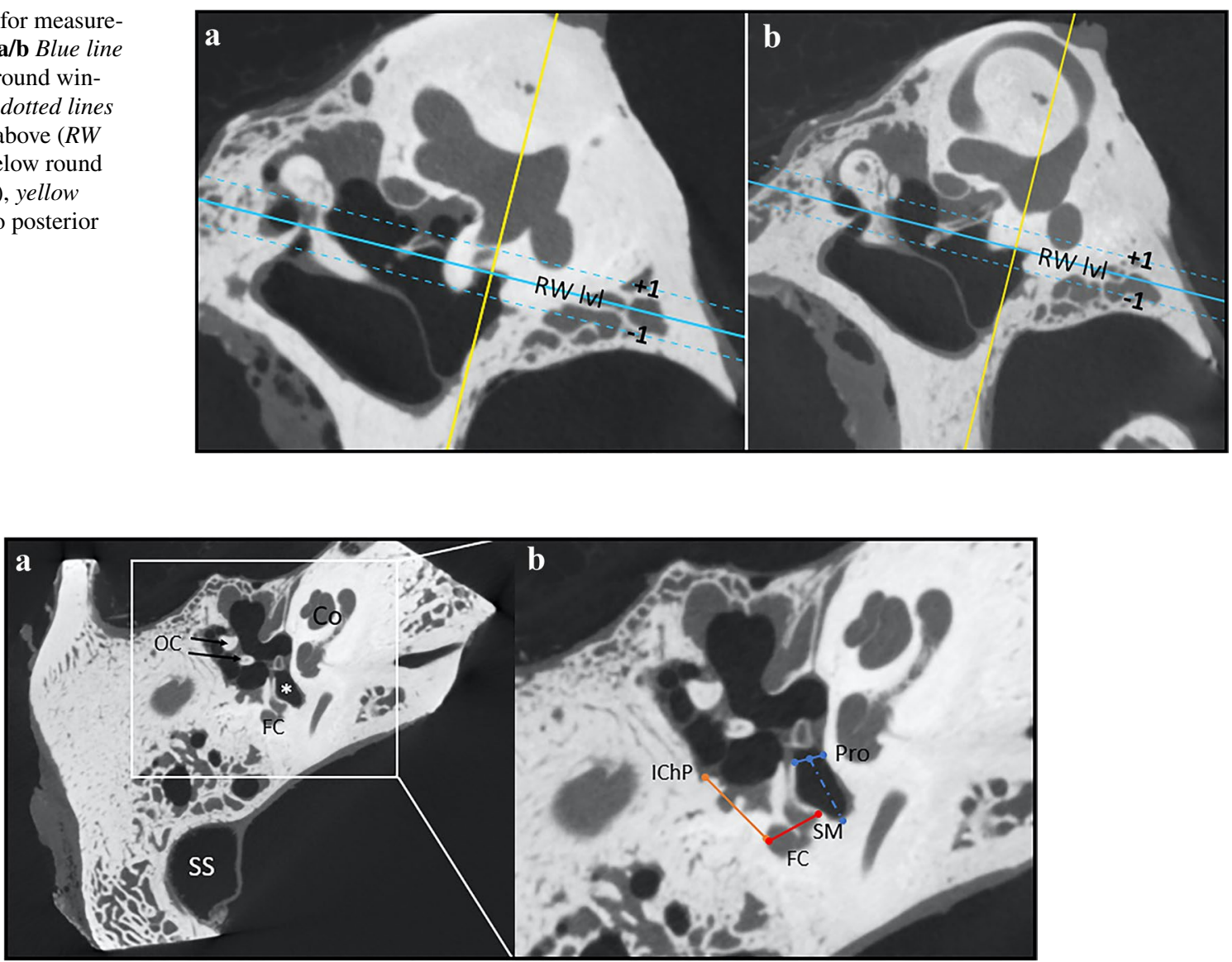

Fig. 3 a General overview of the measurements area b Detailed view shows the distances measured; $O C$ ossicular chain, $S S$ sigmoid sinus, Co cochlea, FC facial canal, white asterisk sinus tympani, IChP iter chordae posterius, Pro promontory, SM stapedius muscle, orange line

\section{Results}

There was possible to perform measurements of the tympanic sinus based on available micro- Computed Tomography. The CT-scans analysis provided enough information and the anatomical structures such as stapes head, round window, tympanic sinus space were delineated on the CT scan.

\section{Descriptive statistics}

\section{Tympanic sinus width}

The average width of the tympanic sinus reached the highest values at the level $1 \mathrm{~mm}$ below the round window and amounted to $2.68 \mathrm{~mm}$ (SD 0.76). The width of the tympanic sinus decreased with the higher position of the measurement plane. At the round window level, it was $1.84 \mathrm{~mm}$ (SD 0.61). $1 \mathrm{~mm}$ above round window was 1.175 (SD 0.46). A similar width of posterior tympanotomy (wPT), red line width of facial canal and stapedius muscle chamber $(\mathrm{FN}+\mathrm{SM})$, blue line width of sinus tympani, blue dotted line depth of sinus tympani

trend occurred in the analysis of the maximum and minimum widths of the tympanic sinus.

\section{Tympanic sinus depth}

The highest average tympanic sinus depth was measured at the round window plane and reached the highest value $3.19 \mathrm{~mm}$ (SD 1.03). At the level $1 \mathrm{~mm}$ below the round window it was $2.99 \mathrm{~mm}$ (SD 1.17) and $1 \mathrm{~mm}$ above the round window was $2.88 \mathrm{~mm}$ (SD 0.71). The maximum and minimum depth's values were maintained a similar trend to the average values. There were found four type A tympanic sinuses, ten were classified as type B and two of them-type $\mathrm{C}$, according to Marchioni's classification.

\section{Facial nerve/stapedius muscle width (FN + SM)}

The $\mathrm{FN}+\mathrm{SM}$ achieved the highest average values at the round window plane $3.32 \mathrm{~mm}$ (SD 0.60). The lowest average 
Fig. 4 a View of facial canal in its plane b View of chorda tympani course $\mathbf{c}$ The route of for intraoperative ECochG measurements; $F C$ facial canal, $T M$ tympanic membrane, $A n$ mastoid antrum, $O C$ ossicular chain, three black arrows iter chordae posterius, two black arrows iter chordae anterius, LSC lateral semicircular canal, red dotted line chordo-facial angle - the area of posterior tympanotomy, red line width of sinus tympani, blue line with arrowhead possible route to sinus tympani through posterior tympanotomy placement the ball electrode
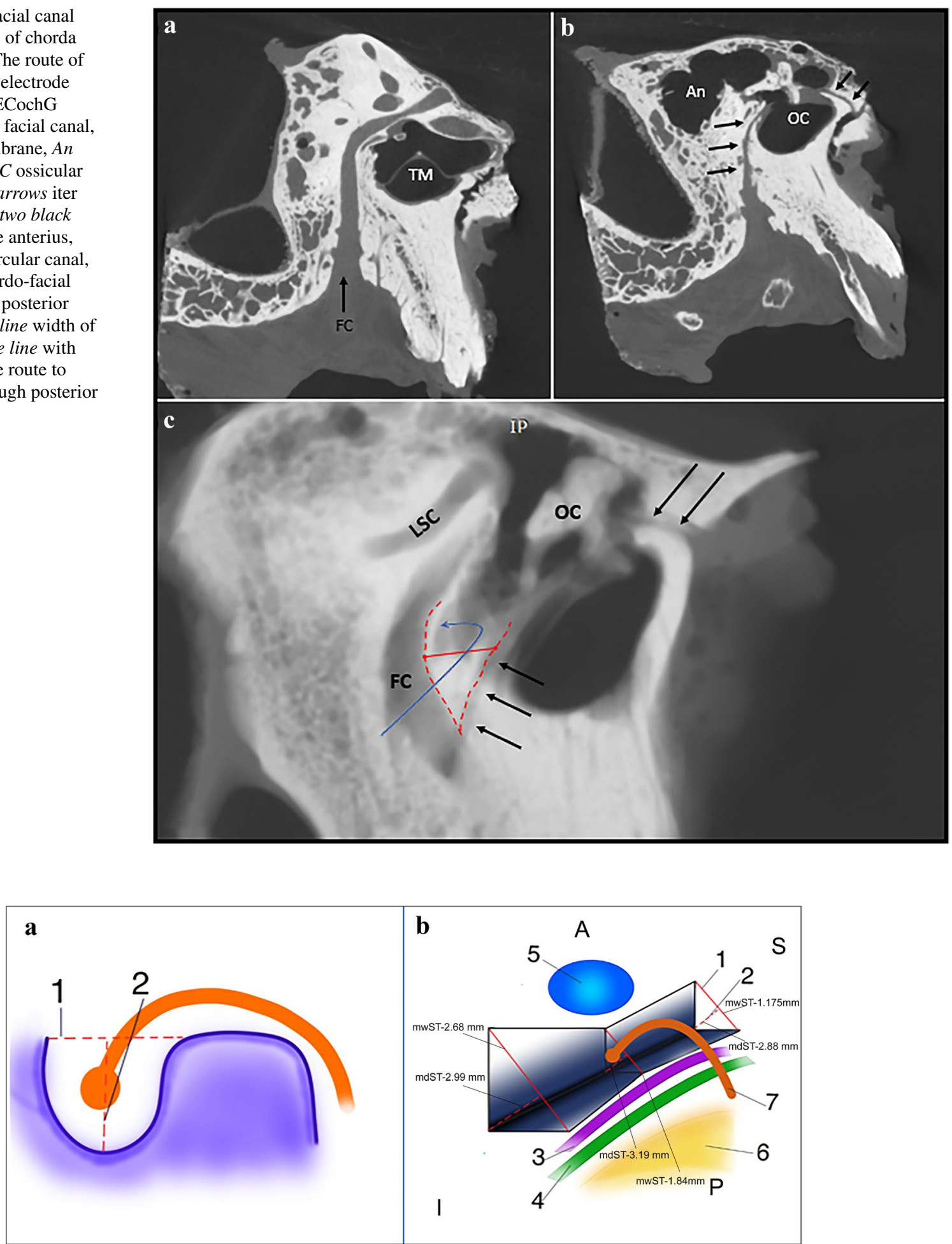

Fig. 5 a A way to anchor the spherical tip of hook electrode $\mathbf{b}$ The estimated shape of sinus tympani with its positional relationship with structures in vicinity. Directions: S- superior, I- inferior, A- anterior, P-posterior 1. width of sinus tympani (wPT), 2. depth of sinus

minimum and maximum values were calculated at the $1 \mathrm{~mm}$ above the round window plane.
tympani(dST), 3. stapedius muscle, 4. facial nerve, 5. round window, 6 . bed created during the antromastoidectomy. mwST- mean width value of sinus tympani, mdST- mean depth value of sinus tympani

The posterior tympanotomy width — the distance between the facial nerve and chorda tympani. 
The highest average posterior tympanotomy width was $2.91 \mathrm{~mm}$ (SD 0.67).

\section{Data comparing}

A statistical comparison of the differences between $\mathrm{FN}+\mathrm{SM}, \mathrm{wST}$-RW, and dST_RW on three measurements levels. First, in the Kruskal Wallis analysis, statistical differences between parameter levels were calculated. Only in the wST_RW parameter, significant statistical differences were obtained. Then, the Mann-Whitney $U$ test was used to calculate the significance levels for each wST_RW level. The lengths of each wST_RW level were statistically significantly different from each other ( $p$ value $<0.05$ ) (Table 2$)$.

\section{The tympanic sinus shape}

Based on the collected data, it can be assumed that the shape of the tympanic sinus is like a trough with the narrowest and deepest dimensions in the middle part (Fig. 5).

\section{Discussion}

The variation in the size and shape of the tympanic sinus has been previously investigated in numerous studies.

The surgical access to sinus tympani may be challenging, because of the localization of the facial nerve and the stapedial muscle with its tendon [2].

The hearing improvement is one of the major aim of otologic surgery. Electrocochleography (ECochG) is also an objective method of cochlear function monitoring during near real-time measurements. It allows an indirect assessment of the effectiveness of the ossicular chain reconstruction (by measuring of the cochlea activity) during tympanoplasty.

A method for measuring of the hearing improvement during tympanoplasty has been introduced by Morawski et al. [19]. According to their description, in the first step, canal wall up technique is performed with posterior tympanotomy and ossicular chain reconstruction. In the next stage, earphones are inserted into external auditory meatus and through posterior tympanotomy needle electrode is placed at the nearest point of the round window niche. During measurement, headphones generates acoustic signals at frequencies $500 \mathrm{~Hz}, 1000 \mathrm{~Hz}, 2000 \mathrm{~Hz}, 4000 \mathrm{~Hz}$ and intensities that decrease from $90 \mathrm{~dB}$ by $10 \mathrm{~dB}$ to the hearing threshold. Needle electrode detects electrical responses from the cochlea. Hearing threshold is the lowest sound intensity that generates the electrical response of the cochlea. This method is especially useful in the cases of patients after multiple ossiculoplasties without hearing improvement.

\section{Shape}

Basing on the measurements in the current study, the tympanic sinus has a trough-shape; the middle part has the narrowest and deepest dimensions. Wang et al. classified ST into three categories: the cup-shaped, the pear-shaped and the boot-shaped, the last one was presented only in patients

Table 3 Measurements (width and depth) and shape evaluation of tympanic sinus (ST) in the literature

\begin{tabular}{|c|c|c|c|c|c|}
\hline Author & Year & Sample type & ST width $(\mathrm{mm})$ & ST depth (mm) & ST shape \\
\hline Abdel Baki et al [1] & 2002 & Endoscopy & $2.4(1.2-3.3)$ & $2.6(0.9-6.1)$ & \\
\hline Baklaci et al [3] & 2019 & HRCT & - & $1.41 \pm 0.68(0.20-3.00)$ & \\
\hline Bekci et al [4] & 2020 & $3 \mathrm{D} \mathrm{CT}$ & - & - & $\begin{array}{l}\text { ST volume rise } \\
\text { with petrous } \\
\text { bone pneuma- } \\
\text { tization }\end{array}$ \\
\hline Cheita et al [6] & 2010 & Cadaver & $2.00(1.24-2.76)$ & $2.74(0.5-6.2)$ & \\
\hline Chen et al [7] & 2005 & HRCT & $1.98( \pm 0.71)$ & $2.25( \pm 0.91)$ & \\
\hline Donaldson et al [9] & 1970 & Cadaver & - & 3.75 & \\
\hline Kumar et al [13] & 2019 & Cadaver & $1-3($ mean 2.2$)$ & 5 (mean 1.72) & \\
\hline Mazziotti et al [18] & 2006 & $\mathrm{CT}$ & $2.50(1.5-3.2)$ & $3(2.3-4.8)$ & \\
\hline Niemczyk et al [20] & 2003 & Cadaver & $2.23(1.0-3.5)$ & & oval \\
\hline Ozturan et al [22] & 1996 & Cadaver & $1.49(0.49-3.87)$ & $2.06( \pm 0.60)$ & \\
\hline Parlier-Cuau et al [23] & 1998 & HRCT & - & $2.7(1-9)$ & \\
\hline Saito et al. [26] & 1971 & Cavader & $0.96-3.22($ mean 2.14$)$ & $2.93(0.61-5.87)$ & \\
\hline Wang et al [29] & 2015 & 3D HRCT & - & - & $\begin{array}{l}\text { Cup-shaped, the } \\
\text { pear-shaped } \\
\text { and the boot- } \\
\text { shaped }\end{array}$ \\
\hline
\end{tabular}


with congenital aural atresia [29]. In the literature, the shape of sinus tympani was also described as oval [20]

Nitek et al. described in most cases the tympanic sinus as elliptical in shape and its long diameter lies in the vertical plane [21]. Marchioni et al. had proposed three types of ST, that can be detected and classified by HRCT scan: Type A (a limited ST), Type B (a deep ST), and Type C (a deep ST with a posterior extension) [17].

The factors, which affect the variations in shape, volume and the size of the sinus tympani are unclear. The width and depth of the sinus tympani may vary in different anatomic morphology and pneumatization pattern of the temporal bone. In study by Bekci et al., the volume of sinus tympani was significantly greater in patients with pneumatized petrous apex [4]. Our study showed that dimensions of the tympanic sinus were highly variable. Both the width and depth of the sinus tympani were measured in numerous studies and in most of them the measurements are consistent with those in our series $[1,3,6,7,9,13,18,20-23,26]$.

\section{Width}

In the current study, sinus tympani width reached the highest values at the level $1 \mathrm{~mm}$ below the round window and amounted to $2.68 \mathrm{~mm}$ (SD 0.76) and the values decreased with the higher position of the measurement plane. The results with regard to the width are in consensus with several studies, presented in the Table 3.

\section{Depth}

In the literature, the measurements of the ST depth were provided usually at one level. In the current study, highest average tympanic sinus depth was measured at the level of round window plane $(3.19 \mathrm{~mm})$ and the measurement decreased at the level $1 \mathrm{~mm}$ below the round window $(2.99 \mathrm{~mm})$ and $1 \mathrm{~mm}$ above the round window $(2.88 \mathrm{~mm})$. The results presented in the literature has shown similar measurements were obtained both from studies based on cadavers, endoscopic and radiologic examination. In the study by Niemczyk et al., the correlation between a deeper tympanic sinus and a more prominent facial canal was observed [20]. In the study by Parlier-Cuau et al., the maximal measurement was $9 \mathrm{~mm}$, according to authors ST remained independent of the mastoid cells. The deepened ST may significantly increase the risk of incomplete excision by the classical transmeatal route [23].

\section{Facial nerve/stapedius muscle distance (FN + SM)}

According to our knowledge, in the literature there are no descriptions of a specific design of the electrode, which could be used for intraoperative hearing monitoring during middle ear or cochlea surgery through posterior tympanotomy approach $[8,25]$.

Reported intraoperative ECochG is performed with standard needle electrodes, which does not provide expected stabilization during the procedure. The solution could be designing a ball or needle electrodes, with a shape of the hook, which would allow stable fixation of the electrode in the sinus tympani monitoring $[10,12,14]$.

The dimensions of ST should be taken into account in constructing the ball electrode, designed for electrocochleography through posterior tympanotomy approach. Combined values of ST width and depth, and the width of posterior tympanotomy may be useful to assess the diameter of the probe, used during electrocochleography. To estimate the size of the ball electrode, the lowest measurement of the width and depth should be assessed. In the planes used for measurements in the current study, the minimal measurements $\mathrm{wST} \sim 0,5 \mathrm{~mm} \mathrm{dST} \sim 1,1 \mathrm{~mm}$. The distance between $1 \mathrm{~mm}$ below the round window and $1 \mathrm{~mm}$ above the round window is considered to be the range of insertion of the electrode. Therefore, the estimated height of ST was $2 \mathrm{~mm}$. The FN + SM value corresponds to possible radius of hookshaped probe, which may be used in intraoperative hearing monitoring. The measurements may be used to design and produce a custom form of the electrode, applied in ear and cochlear surgery (Fig. 6).

The hook-shaped electrode is designed due to the conformation of the retrotympanum and operative approach. The length of the ascending and descending parts of the hook results from the depth of the tympanic sinus and the shape of the bed created during the antromastoidectomy. The shape and size of the rounded center portion of the hook are due to access through the posterior tympanotomy approach in that the length of the FN / SM is the width of the access window. It should be underlined, that during the posterior

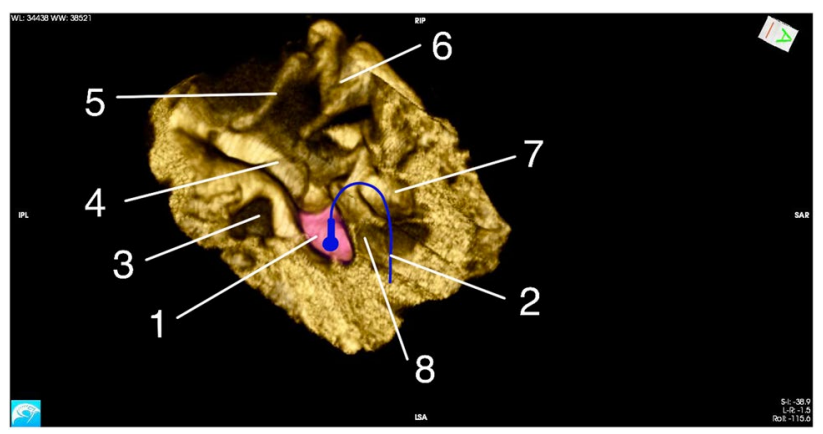

Fig. 6 Micro-CT reconstruction presenting sinus tympani with the schematic placement of the ball electrode for electrocochleography. 1. Sinus tympani (pink color) 2. Electrode 3. Round window 4. Stapes 5. Malleus 6. Incus 7. Facial nerve recess 8 . Facial nerve and stapedius muscle 
tympanotomy, both the facial nerve and the stapedius muscles are kept intact.

The electrode is inserted through the posterior tympanotomy similar to a needle electrode. Then it is stabilized on the "bulging" of the facial nerve (pyramidal eminence/pyramidal ridge) and the stapedius muscle at the level of the round window. The spherical tip of the electrode prevents damage of the tympanic mucosa, reducing the probability of bleeding, and increasing the probability of a correct ECochG measurements as it has greater surface of contact than the needle.

\section{Conclusions}

1. Evaluated morphology of sinus tympani revealed the shape of a trough with the narrowest and deepest dimensions in the middle part of the round window. The values increase below and above the level of round window.

2. Minimal measurements of sinus tympani depth and width are $1.01 \mathrm{~mm}$ and $1.84 \mathrm{~mm}$. The dimensions should be taken into account in constructing the ball electrode, designed for electrocochleography through posterior tympanotomy approach.

Acknowledgements This work was supported by grants from the National Centre for Research and Development under the PBS III Program (ID 244803).

Author contributions MB: Manuscript writing/editing. TW: Data collection or management, manuscript writing/editing. JS: Data collection or management, data analysis, manuscript writing/editing. KN: Manuscript writing/editing, protocol/project development.

Funding This paper was based on results of research that was cofinanced by The National Centre for Research and Development under the PBS III Program (ID 244803) "Elaboration of innovative method of direct stimulation of inner ear structures using bone conduction".

Availability of data and material Data and materials are available from the authors upon request.

Code availability Software applications are used under license.

\section{Declarations}

Conflict of interest The authors declare that they have no conflict of interest.

Ethical approval This retrospective study was approved by the Ethics Committee of Medical University of Warsaw (Decision Number $\mathrm{KB} / 69 / 2015$ ), and abides by the 1964 Helsinki Declaration and its later amendments or comparable ethical standards.

Consent to participate All authors consented to participate in the study.
Consent for publication All authors consented to the publication of the article.

Open Access This article is licensed under a Creative Commons Attribution 4.0 International License, which permits use, sharing, adaptation, distribution and reproduction in any medium or format, as long as you give appropriate credit to the original author(s) and the source, provide a link to the Creative Commons licence, and indicate if changes were made. The images or other third party material in this article are included in the article's Creative Commons licence, unless indicated otherwise in a credit line to the material. If material is not included in the article's Creative Commons licence and your intended use is not permitted by statutory regulation or exceeds the permitted use, you will need to obtain permission directly from the copyright holder. To view a copy of this licence, visit http://creativecommons.org/licenses/by/4.0/.

\section{References}

1. Abdel Baki F, El Dine MB, El Saiid I, Bakry M (2002) Sinus tympani endoscopic anatomy. Otolaryngol Head Neck Surg 127:158-162. https://doi.org/10.1067/mhn.2002.127588

2. Aslan A, Guclu G, Tekdemir I, Elhan A (2004) Anatomic limitations of posterior exposure of the sinus tympani. Otolaryngol Head Neck Surg 131:457-460. https://doi.org/10.1016/j.otohns. 2004.03.028

3. Baklaci D, Kuzucu I, Guler I, Akbal S, Kum NY, Yildirim GK, Parlak IS, Kum RO, Ozcan M (2019) Effect of mastoid bone pneumatization on the conformation and depth of the sinus tympani, a high-resolution computed tomography study. Surg Radiol Anat 41:921-926. https://doi.org/10.1007/s00276-019-02246-3

4. Bekci T, Hizli O, Ozturk M, Yildirim G (2020) Quantitative threedimensional computed tomography analysis of sinus tympani volume in temporal bones with petrous apex pneumatization. Auris Nasus Larynx 47:587-592. https://doi.org/10.1016/j.anl.2020.01. 009

5. Burd C, Pai I, Connor S (2020) Imaging anatomy of the retrotympanum: variants and their surgical implications. Br J Radiol 93:20190677. https://doi.org/10.1259/bjr.20190677

6. Cheita AC, Maru N, Mogoanta CA, Ionita E (2010) The recesses of the retrotympanum. Romanian J Morphol Embryol 51:61-68

7. Chen B, Yin S, Shen P (2005) The feasibility of the retrofacial approach to the pediatric sinus tympani. Otolaryngol Head Neck Surg 133:780-785. https://doi.org/10.1016/j.otohns.2005.06.011

8. Dalbert A, Pfiffner F, Roosli C, Thoele K, Sim JH, Gerig R, Huber AM (2015) Extra- and intracochlear electrocochleography in cochlear implant recipients. Audiol Neurootol 20:339-348. https://doi.org/10.1159/000438742

9. Donaldson JA, Anson BJ, Warpeha RL, Rensink MJ (1970) The surgical anatomy of the sinus tympani. Arch Otolaryngol 91:219-227

10. Haumann S, Imsiecke M, Bauernfeind G, Buchner A, Helmstaedter V, Lenarz T, Salcher RB (2019) Monitoring of the inner ear function during and after cochlear implant insertion using electrocochleography. Trends Hear 23:2331216519833567. https://doi. org/10.1177/2331216519833567

11. Höhmann D (1992) Intraoperative monitoring with transtympanic electrocochleography. HNO 40:133-139

12. Krieg SM, Kempf L, Droese D, Rosahl SK, Meyer B, Lehmberg J (2014) Superiority of tympanic ball electrodes over mastoid needle electrodes for intraoperative monitoring of hearing function. J Neurosurg 120:1042-1047. https://doi.org/10.3171/2014.1.Jns13 396 
13. Kumar BYP, Venugopal D, Parashuram R, Veenapani MK, Subhash C, Sunil KC, Pardikar SS (2018) Dimensions and morphology of the sinus tympani: an anatomical study. Int J Otorhinolaryngol Head Neck Surg. https://doi.org/10.18203/issn. 2454-5929.ijohns 20185060

14. Lenarz T, Ernst A (1992) Intraoperative monitoring by transtympanic electrocochleography and brainstem electrical response audiometry in acoustic neuroma surgery. Eur Arch Otorhinolaryngol 249:257-262

15. Marchioni D, Mattioli F, Alicandri-Ciufelli M, Presutti L (2009) Transcanal endoscopic approach to the sinus tympani: a clinical report. Otol Neurotol 30:758-765

16. Marchioni D, Molteni G, Presutti L (2011) Endoscopic anatomy of the middle ear. Indian J Otolaryngol Head Neck Surg 63:101-113. https://doi.org/10.1007/s12070-011-0159-0

17. Marchioni D, Valerini S, Mattioli F, Alicandri-Ciufelli M, Presutti L (2015) Radiological assessment of the sinus tympani: temporal bone HRCT analyses and surgically related findings. Surg Radiol Anat 37:385-392. https://doi.org/10.1007/s00276-014-1366-7

18. Mazziotti S, Arceri F, Vinci S, Salamone I, Racchiusa S, Pandolfo I (2006) Role of coronal oblique reconstruction as a complement to CT study of the temporal bone: normal anatomy. Radiol Med 111:607-617. https://doi.org/10.1007/s11547-006-0055-y

19. Morawski K, Niemczyk K, Sokolowski J, Hryciuk A, Bartoszewicz R (2014) Intraoperative monitoring of hearing improvement during ossiculoplasty by Laser-Doppler vibrometry, auditory brainstem responses, and electrocochleography. Otolaryngol Head Neck Surg 150:1043-1047. https://doi.org/10.1177/0194599814 524365

20. Niemczyk K, Nitek S, Wysocki J, Bruzgielewicz A (2003) Anatomy of sinus tympani. Otolaryngol Pol 57:389-393

21. Nitek S, Wysocki J, Niemczyk K, Ungier E (2006) The anatomy of the tympanic sinus. Folia Morphol 65:195-199

22. Ozturan O, Bauer CA, Miller CC 3rd, Jenkins HA (1996) Dimensions of the sinus tympani and its surgical access via a retrofacial approach. Ann Otol Rhinol Laryngol 105:776-783. https://doi. org/10.1177/000348949610501004
23. Parlier-Cuau C, Champsaur P, Perrin E, Rabischong P, Lassau JP (1998) High-resolution computed tomographic study of the retrotympanum. Anatomic correlations Surg Radiol Anat 20:215-220

24. Pickett BP, Cail WS, Lambert PR (1995) Sinus tympani: anatomic considerations, computed tomography, and a discussion of the retrofacial approach for removal of disease. Am J Otol 16:741-750

25. Pobożny I, Lachowska M, Bartoszewicz R, Niemczyk K (2020) Detailed insight into transtympanic electrocochleography (TTECochG) and direct cochlear nerve action potential (CNAP) for intraoperative hearing monitoring in patients with vestibular schwannoma-methodology of measurements and interpretation of results. Otolaryngol Pol 9:1-8. https://doi.org/10.5604/01.3001. 0014.3368

26. Saito R, Igarashi M, Alford BR, Guilford FR (1971) Anatomical measurement of the sinus tympani. Study of horizontal serial sections of the human temporal bone. Arch Otolaryngol 94:418-425

27. Smith DER (2008) Complications in head and neck surgery. Elsevier

28. Visvanathan V, Morrissey MS (2015) Anatomical variations of the temporal bone on high-resolution computed tomography imaging: how common are they? J Laryngol Otol 129:634-637. https://doi. org/10.1017/S0022215115001115

29. Wang Z, Hou Q, Wang P, Sun Z, Fan Y, Wang Y, Xue H, Jin Z, Chen $X$ (2015) The image variations in mastoid segment of facial nerve and sinus tympani in congenital aural atresia by HRCT and 3D VR CT Int. J Pediatr Otorhinolaryngol 79:1412-1417. https:// doi.org/10.1016/j.ijporl.2015.06.014

30. Wojciechowski T, Skadorwa T, Nève de Mévergnies JG, Niemczyk K (2020) Microtomographic morphometry of the stapedius muscle and its tendon. Anat Sci Int 95:31-37. https://doi.org/10. 1007/s12565-019-00490-6

Publisher's Note Springer Nature remains neutral with regard to jurisdictional claims in published maps and institutional affiliations. 